\title{
The Degree to Which the Activity Manual Includes an "Interactive Curriculum of Activity Classes" for Life Skills and Secondary School Student
}

\author{
A.D. Nasser Ahmad Al-Khawaldeh \\ University of Jordan / College of Educational Sciences \\ A. Amani Odeh Matar \\ Master of Curriculum and Instruction / General Curriculum
}

\begin{abstract}
This study aimed to know the degree to which the activities guide includes the "interactive curriculum for activity classes" for life skills and the acquisition of students for them. To achieve the goals of this study, a questionnaire consisting of (24) items was distributed to high school students, (150) students in Latin schools, Madaba. as well as through the content analysis of the activities guide "interactive curriculum for activity classes"The researcher used the descriptive survey method, and the study concluded that the degree of inclusion of life skills in the activities guide "interactive curriculum for activity classes" was low, and with regard to the degree of secondary school students' acquisition of life skills, the study showed that the degree of secondary school students acquiring life skills available in the guide Activities "The interactive curriculum for activity classes" in Jordan an average degree was with an arithmetic average (2.95\%). Based on the results of the study, the study recommended making use of the results of this study to review the guide for activities "the interactive curriculum for activity classes" and taking into account the priority of life skills.
\end{abstract}

Keywords: life skills, interactive curriculum, high school students.

DOI: $10.7176 / \mathrm{JLPG} / 104-09$

Publication date: December $31^{\text {st }} 2020$

\section{Introduction}

School activities are a driving force that must be incorporated into the learning and teaching process; By achieving effective students, they have a sense of pride, a sense of self-importance at the national and global level, in addition to their belief that every success achieved on this changing world is linked to the students 'ability to learn, and considering them qualified, because they are teachers of the future who are able to translate what they have learned In school in their life which is constantly changing.

Depending on the constructivism of Jordanian curricula on the outcomes and criteria, and its emphasis on interactive dialogue, and the meaningful and enjoyable debate that exists between the teacher and the learner in order to engage, deepen the research, and exchange ideas and experiences; That pushes the student to ask, confront problems related to it, and look at it in another perspective. The Ministry of Education found that activities in general are concerned with developing the skills, values, and capabilities of the student within the applied practical context based on theoretical and practical understanding, and balance between in-depth and expansion of content And its organization around several ideas and principles that are basically based on the student's previous learning, and their capabilities to rebuild it to achieve his personality.(Ministry of Education, 2019)

Activities have an important role that revolves around transforming students 'convictions from mastery of information and data to making these data a basis for mastery of knowledge. With what it includes of skills and values, with the aim of building a balanced personality of students who enjoy comprehensive, renewable and comprehensive competencies, and which have skills (thinking, creativity, and higher thinking), within a framework of supportive values that enable knowledge, and the skills that students have to solve their life problems, in appropriate ways Out of the box. Therefore, the concept of school activities in general is a complex concept. Activities that develop students' inclinations and desires overlap with activities related to the curriculum and practical teaching methods, in addition to activities based on linking life concepts to the subjects; That works to stabilize the values according to the national and global dimensions (Al-Youssef, 2013).

Forms of school activities:

1. General school activities: which are multiplied according to several axes (cultural, scientific, literary, sports, technological, health, etc.), as each axis is divided into multiple sections, for example sports activity is divided into clubs including (football, swimming, and gymnastics) The school teachers control these activities, according to their specializations, the number of students, their preferences and capabilities, the school's development plan and its ambition in entering competitions at the governorate or kingdom level, the size of the school facilities and conditions, and their capabilities.

2. The activities related to the academic subjects: based on the transformation of student education from the 
theoretical side to the practical side; Which helps to raise learning ratios, increases polite and moral reinforcement, and develops classroom environment conditions based on fun learning; Through activities that support dialogue, stimulate thinking, constructive criticism, multiple opinions, and the ability to make decisions. The activities do not need an additional teacher, but rather a teacher trained in teaching methods, communication, and the ability to choose and prepare appropriate activities for students.

3. Classroom activities: that are given during two scheduled classes within the weekly program for each class. These activities are divided into several main areas and sub-fields of concepts available in the study materials, so each concept is formulated with one or more activities for students, in ways that achieve them contact, communication, dialogue and pleasure (Ministry of Education, 2020).

The activities guide dealt with the "interactive curriculum for activity classes", on four main axis distributed over 72 activities: (thinking skills, environment and work, civil values and ideals, technical and beauty taste), as it covered the axes of values and civil ideals, and thinking skills, activities of the guide in the form of Whole; Having examined several values, and the role of the teacher in it is directed and facilitated, and to stimulate dialogue about the content of these activities; In easy ways to provide students with skills from multiple levels, in addition to the skill of creativity. As for the themes of the environment and work, artistic taste and beauty, they are covered less in the activities guide, as they must be achieved through the existing dialogue between the teacher and the learner, or by offering examples that help clarify, and deepen understanding.

Based on the foregoing, it is the responsibility of the teacher based on the implementation of the content of the activities guide, the function of notifying the activity closest to the level of development for the students of the class, and pre-planning it, and determining additional products and contents for each activity, in addition to the procedures and strategies that are followed in implementing these activities, in a way It brings benefit and enjoyment. Teachers wishing to give a guide to activities, who are discharged to perform this task, regardless of their specialties and provided with training by a committee of educational supervisors; As field trainers, to be able to train teachers, and ensure their performance competencies; To achieve the activities of the guide before its actual implementation (Ministry of Education, 2019).

The objectives of the activities guide, "the interactive curriculum of activity classes":

1. Educational technical support to schools in general to achieve the minimum level of justice, and equality in front of the accompanying discrepancy, and competencies in each school.

2. To focus on the practical side rather than the theoretical side.

3. Presenting scholastic and descriptive activities in support of the contents of the concepts crossed in the school subjects, and focusing on higher thinking skills.

4. Developing students' personal aspects (mental, emotional, and social) in a balanced way.

5. disseminate fun and interaction in the school environment, in order to prevail the attractive participatory.

6. Developing the capacities of the staff which is responsible for the success of the activities guide, and achieving its goals through training programs before and after implementing activities (Ministry of Education, 2019).

Since the activities of the interactive curriculum for activity clasess are based on four main axes, that focus on life skills, such as (social, academic, preventive, and environmental) skill, which the Ministry of Education in Jordan cared about during its review of school curricula in general, as The Ministry has taken procedural steps to develop the content of all these curricula, and all textbooks, through community participation, and following the global development, taking into account the developmental stages of students (Shawish, 2010).

Life skills have received a lot of attention since the last century, but they acquire a global nature and after that they were adopted by the United Nations Educational, Scientific and Cultural Organization (UNESCO) and other international organizations (Hayek, 2014).

It is the life skills and abilities (mental, sensory, and emotional) that help the student to face problems and the ability to solve them. It has been defined by the United Nations International Children's Emergency Fund (UNICEF) as the necessary social and psychological capabilities for positive adaptive behaviors; That enables the student to deal with life challenges effectively and confidently, and has been classified into 3 categories (personal communication and effective communication skills, personal skills based on character development and strengthening, ability to self-management, and cognitive skills to analyze and understand information in greater depth) (UNICEF , 2009).

The World Health Organization (WHO) has included ten life skills which are (problem solving, critical thinking, decision making, creative thinking, communication and communication, self-awareness, personal relationships, emotion management, emotion clamping and stress management), as they form the first stages From the age of students, a golden opportunity to acquire these skills to meet the challenges of daily life with high skill, when these stages of students offer various educational experiences, in many of his life situations, and enable him to respond to the rapid changes and developments of the age (Ige, 2011).

Based on the above, it is necessary to teach students basic life skills; To nurture students a strong nurturing from all moral, spiritual, intellectual, physical, and social aspects seriously and precisely, and to provide them with everything they need to face the challenges of the age, which is characterized by globalization and rapid changes, 
so that students can prove their existence and preserve their cultural, human, and cognitive identity, And not to reproduce the identity of the West, and obliterate the mother's identity. In addition to the educational curricula and textbooks, the activities guide "the interactive curriculum for activity classes" is able to include life skills, as the existing reciprocal relationship between the activities guide and educational curricula helps in this, given the diversity of life skills; That should be given to students, as the activities guide is one of the most closely related curricula to the surrounding environment for students, and the most interactive, in addition to the widening of the practical side in it, and its flexibility and fun, so this study came to investigate the degree of inclusion of the activities guide for the "interactive curriculum of activity classes" for life skills and students gain it.

\section{The study Problem:}

Based on the degree of interest of the Ministry of Education in life skills, it came up with the adoption of a draft activities guide, "the interactive curriculum for activity classes" to contribute to giving students an opportunity to develop their life skills, and confirm themselves with the educational development plan based on comprehensive quality standards, knowledge economy, and in view of the importance of a guide Activities in preparing students, tending their attitudes toward positivity, belonging to the school consciously, and firmly with the values, and civic ideals of their personalities. And that is through the compatibility between the learning content and its various sources, and considering activities an important part of it, and that learning has not and will not be complete except with theoretical and practical work related to the content of the study material, which is carried out inside or outside the school facilities through the practical nature of the dialogue, and performance by paying attention to the characteristics of the brainstorming meeting, which helps to develop thinking skills, creativity in a realistic way, and the involvement of students in self-evaluation of their interaction, and the mood of this interaction.

Accordingly, the study problem was to determine the degree to which the activities guide includes an "interactive curriculum for activity classes" of life skills and students' acquisition of them, which are represented by the following two questions:

1. What is the degree of inclusion life skills in the activity guide of the interactive curriculum in Jordan?

2. What is the degree of secondary school students' acquisition of life skills that are available in the activities guide "interactive curriculum for activity classes"?

Objectives of the study:

This study aims to define the degree to which activities are included in the "interactive curriculum for activity classes" in Jordan for life skills, in addition to investigating the degree of students' acquisition of life skills available in the activities guide.

\section{The importance of the study:}

This study acquires its importance through the importance that life skills occupy, and perhaps its strength lies in investigating the degree of embedding life skills in the content of the activities guide, by making a list of life skills included in the activities guide, and a list of life skills acquired by students from this guide, as it is possible for curriculum developers, and educational decision-makers in the Ministry of Education by developing the activities of the guide, and adding it to raising the motivation of researchers to conduct more studies in this field, as this research is the first of its kind in analyzing the activities guide - according to the researcher's knowledge - and highlighting the class of students who are the builders of the future.

\section{Terminology of the study:}

The current study will be defined by terms and procedure as follows:

The procedural guide was known procedurally as: it is a guide prepared by the Ministry of Education in Jordan and was applied in schools in (2018-2019) consisting of several classroom and school activities that include a set of cross-concepts of materials Study and able to develop higher-order thinking skills, and provide technical educational support; to achieve the minimum equality, and justice in front of the variation of the material capabilities that differ from one school to another.

Life Skills:

It is a set of social and psychological skills that enable students to make the right decision, the ability to communicate effectively, and provide them with the necessary to face challenges with confidence (UNICEF, 2009). The researchers defined it procedurally: the sensory, mental, and emotional abilities that students gain in Jordanian schools, through the Activities Manual; It is to build an independent, confident and ambitious personality, capable of adapting to the challenges of today's life, and facing them, the ability to solve them, and developing their social behavioral patterns.

\section{The limits of the study:}

The study is determined by the following limits:

1. Thematic limits: The degree of life skills assessment is defined in the activities guide, "the interactive curriculum for activity classes" and the acquisition of students by it.

2. Human limits: The study was limited to a sample of students from Deir Latin schools. 
3. Spatial limits: The study was limited to a sample of students from Deir Latin schools, Madaba branch.

4. Time limits: The study was applied in the academic year 2019-2020.

\section{Previous studies}

Several previous studies related to the subject of the study were reviewed, as they were arranged from newest to oldest as follows:

Abu Saiba, Al-Hadidi (2018) study aimed to identify the degree of availability of life skills included in the English language textbook for the sixth grade in Amman and the degree of students' acquisition of it from the viewpoint of their teachers. The study community and its sample consisted of all pages of the English language book, and was also chosen the English language teachers from three districts of the capital, Amman, by the stratified random method. They numbered (322) male and female teachers. The researchers prepared two tools of study (a form, content analysis) distributed over three main areas: mental, manual (scientific), and social skills. The study reached results were that the degree of availability of life skills included in the English language book for the sixth grade appeared with a high degree in the field of mental skills by a percentage (45\%), and the degree of students' acquisition of life skills came from the viewpoint of their teachers with an average degree and on all three fields of study and the absence of differences according to gender and qualification variables Scientific, level of experience, excluding the gender variable in the area of social skills and in favor of females.

Al-Jazi, Al-Rusaei, Saleh, Al-Hallilat's (2016) study, aimed to know the degree of including life skills in science books for the first three grades in Jordan, where the descriptive approach was used using a content analysis card where a list of life skills that was required to be included in the targeted books was included, included Based on (63) sub-skills, the study concluded that the total number of repetitions of life skills in science books amounted to (764) repeats distributed over seven major life skills, and mental skills were the most repetitive skills received by $(17.93 \%)$, while health and food skills were received Preventive and environmental skills are to a low degree, while emotional skills are not included at all.

Abboud's (2016) study aimed to analyze the life skills included in the books of social studies for the secondary stage in Jordan prescribed by the Jordanian Ministry of Education for the academic year 2015/2016 AD and included five study books, the descriptive analytical approach was used by developing a content analysis tool to identify the life skills included in the books that included four dimensions of life skills, which are: After intellectual and scientific skills, and sub-skills (37) subdivided them, and the result of the study focused on environmental life skills for the needs of students in the secondary stage for it and the emergence of a lack of focusing on some of them.

Sarmad, Habiby and Arvantan (2012) conducted a study aimed to investigat life skills in basic science textbooks, the descriptive analytical approach was used through the content analysis card. The results indicated that thinking skills (analytical and creative) were the most frequent $(17,55 \%)$, and basic skills ranked last with the lowest frequency $(1.69 \%)$.

Eteokleous (2011) conducted a study aimed to know the extent of assessing the social studies curriculum and its effect on developing social skills in Cyprus, and used the descriptive survey method by distributing the questionnaire tool to a sample of (303) students, and the results showed that the social studies curriculum has a major role in developing the social skills of students.

The previous studies have been used to write the theoretical framework and develop the tool, and the current study differs from previous studies as it directly addressed life skills and the importance of including them, analyzing them, and applying them in the activities guide, "the interactive curriculum for activity classes" in all classes, and this distinguishes the current study from others previous studies, in addition to the knowledge of the two researchers; it is one of the first studies that deal with the degree to which the activities guide includes the "interactive curriculum of activity classes" for life skills and students' acquisition of them.

\section{Study methodology:}

In order to achieve the aims of the study, a descriptive and analytical approach was used.

Study population and sample:

The study population consisted of all secondary school students in Madaba Latin Schools who were studying during the semester of the year 2019/2020. The number of the sample is (1239) male and female students according to the statistics of the Latin schools. (150) male and female students from the secondary stage in Deir Al-Latin schools were selected, based on the random stratified sample according to the random sample table for a known population.

\section{The study tools}

The researchers developed two study tools, the questionnaire and the content analysis, after referring to theoretical literature and previous studies.

First: the questionnaire 
The study tool was developed by referring to theoretical literature and previous studies with the aim of developing the study tool in its initial form to know the degree to which the activities guide includes an "interactive curriculum for activity classes" for life skills and students' acquisition of them, as the tool's paragraphs reached (24) paragraphs, and they were designed on the basis of Likert scale )) Five-dimensional, the paragraphs were constructed in a positive direction and weights were given to the paragraphs as follows: strongly agreed five degrees, agreed: four degrees, somewhat agree: three degrees, disagree:: two degrees, strongly disagree: one degree.

Validate of the study tool:

The tool's content validity was confirmed by using face validity by presenting it to a group of arbitrators, from faculty experience and specialization members in Jordanian universities to express their observations in terms of determining the degree of appropriateness of the paragraphs and their comprehensiveness to measure the area in which those paragraphs were mentioned, and the degree of the affiliation of these paragraphs to the field in which they were mentioned, the degree of clarity of the paragraphs, their linguistic and grammatical integrity, and the statement of the proposed amendments to the paragraphs, $(80 \%)$ of the arbitrators' observations are adopted in general, without neglecting to make the proposed amendments to an amendment in the linguistic formulation of the paragraphs, after which a tool was produced the study is in its final form.

The stability of the study tool:

Stability coefficient was extracted by using the Cronbach's Alpha formula for internal consistency, as the study tool was applied to (20) individuals from the study community and outside it's sample with a time difference of two times (14) days, and the stability coefficient for the paragraphs of the questionnaire as a whole was a ( 0.87) percentage. It was high but it is a satisfactory coefficient of research to conduct the study for researchers.

The content analysis is the second study tool, which was used after reviewing previous researches and studies related to the subject of the study and to reach the goals of the study to monitor life skills that can be included in the activities guide, which is one of the most used tools in the analysis of education curricula, it is an analysis tool, a description In general, the content is approved as a unit of analysis.

The stability of the tool

The stability of the analysis was verified by using the method of stability over time, using it to analyze the content of the activities guide, through the researchers analyzing a random sample of the content of the activities guide, "the interactive curriculum of activity classes ", and then the researchers analyzed it again after the first analysis process and with a time limit (21) Days, and then the stability coefficient was calculated according to the following H.listi equation:

$$
\text { Stability coefficient }=\text { number of times agreed between first and second analysis }
$$

$$
\mathrm{x} 100 \%
$$

$$
\text { The number of times the agreement }+ \text { the difference times }
$$

The stability coefficient has reached (90.2), and this is a percentage that can be assured.

Statistical processing:

Statistical treatments for data were performed in this study using the Statistical Package for Social Sciences (SPSS). The results

The following is a presentation of the study results by answering the study questions:

The first question: What is the degree of inclusion the life skills in the activities guide of the "interactive curriculum for activities classes" in Jordan?

To answer this question, iterations and percentages were extracted to know the degree to which the activities guide includes the life skills in the "interactive curriculum of activity classes" in Jordan, and Table (1) shows that:

Table (1):

Repetitions, percentages, and standard deviations for life skills included in the activities guide "Interactive curriculum for activity classes" in Jordan, they are listed in descending order

\begin{tabular}{|l|l|l|l|l|l|}
\hline The number & \multicolumn{1}{|c|}{ Life Skills } & Repetition & Percentage & Rank & Rating \\
\hline 11 & Communication skills & 9 & $7 \%$ & 1 & High \\
\hline 16 & Creative thinking & 7 & $5 \%$ & 2 & High \\
\hline 33 & Respect for the opinion of others & 7 & $5 \%$ & 2 & High \\
\hline 8 & Teamwork & 5 & $4 \%$ & 4 & High \\
\hline 9 & Advance planning & 5 & $4 \%$ & 4 & High \\
\hline 1 & Self expression & 4 & $3 \%$ & 6 & High \\
\hline 4 & Consolidating social values & 4 & $3 \%$ & 6 & High \\
\hline 24 & Observation & 4 & $3 \%$ & 6 & High \\
\hline 41 & automatic expression & 4 & $3 \%$ & 6 & High \\
\hline
\end{tabular}




\begin{tabular}{|c|c|c|c|c|c|}
\hline The number & Life Skills & Repetition & Percentage & Rank & Rating \\
\hline 45 & Creative imagination & 4 & $3 \%$ & 6 & High \\
\hline 12 & Accept the difference & 3 & $2 \%$ & 11 & High \\
\hline 18 & Collaborative work & 3 & $2 \%$ & 11 & High \\
\hline 19 & Multiple solutions to the problem & 3 & $2 \%$ & 11 & High \\
\hline 21 & Problem Solving & 3 & $2 \%$ & 11 & High \\
\hline 23 & Accept criticism & 3 & $2 \%$ & 11 & High \\
\hline 26 & The importance of change in life & 3 & $2 \%$ & 11 & High \\
\hline 30 & time management & 3 & $2 \%$ & 11 & High \\
\hline 37 & Renouncing violence and extremism & 3 & $2 \%$ & 11 & High \\
\hline 59 & Justice & 3 & $2 \%$ & 11 & High \\
\hline 5 & Self-assurance & 2 & $2 \%$ & 20 & Average \\
\hline 7 & Successful leadership & 2 & $2 \%$ & 20 & Average \\
\hline 10 & teamwork & 2 & $2 \%$ & 20 & Average \\
\hline 39 & Analytical thinking & 2 & $2 \%$ & 20 & Average \\
\hline 43 & Take responsibility & 2 & $2 \%$ & 20 & Average \\
\hline 50 & Team play & 2 & $2 \%$ & 20 & Average \\
\hline$\overline{51}$ & Expression by body language & 2 & $2 \%$ & 20 & Average \\
\hline 56 & The conclusion & 2 & $2 \%$ & 20 & Average \\
\hline 57 & Exchange of experiences & 2 & $2 \%$ & 20 & Average \\
\hline 2 & Establishing social relations & 1 & $1 \%$ & 29 & Low \\
\hline 3 & Tolerance & 1 & $1 \%$ & 29 & Low \\
\hline 6 & Knowledge of desired behaviors & 1 & $1 \%$ & 29 & Low \\
\hline 13 & Make comparisons & 1 & $1 \%$ & 29 & Low \\
\hline 14 & Honest positive competition & 1 & $1 \%$ & 29 & Low \\
\hline 15 & The importance of group decision & 1 & $1 \%$ & 29 & Low \\
\hline 17 & Credibility of information & 1 & $1 \%$ & 29 & Low \\
\hline 20 & Coordination of group work & 1 & $1 \%$ & 29 & Low \\
\hline 22 & Perseverance and not giving up & 1 & $1 \%$ & 29 & Low \\
\hline 25 & $\begin{array}{llll}\begin{array}{l}\text { Differentiate between } \\
\text { judgment }\end{array} & \text { description and } \\
\end{array}$ & 1 & $1 \%$ & 29 & Low \\
\hline 27 & Deny the unconfirmed assumptions & 1 & $1 \%$ & 29 & Low \\
\hline 28 & Self development & 1 & $1 \%$ & 29 & Low \\
\hline 29 & Social Intelligence & 1 & $1 \%$ & 29 & Low \\
\hline 31 & Do not hesitate & 1 & $1 \%$ & 29 & Low \\
\hline 32 & Self-affirmation & 1 & $1 \%$ & 29 & Low \\
\hline 34 & respecting others & 1 & $1 \%$ & 29 & Low \\
\hline 35 & The importance of creativity in life & 1 & $1 \%$ & 29 & Low \\
\hline 36 & Etiquette of eating & 1 & $1 \%$ & 29 & Low \\
\hline 38 & role play & 1 & $1 \%$ & 29 & Low \\
\hline 40 & Dialogue with others & 1 & $1 \%$ & 29 & Low \\
\hline 42 & Humility & 1 & $1 \%$ & 29 & Low \\
\hline 44 & changing the tone of your voice & 1 & $1 \%$ & 29 & Low \\
\hline 46 & Focus and attention & 1 & $1 \%$ & 29 & Low \\
\hline 47 & Listen up & 1 & $1 \%$ & 29 & Low \\
\hline 48 & $\begin{array}{llrr}\text { The difference } & \text { between } & \text { a } & \text { person's } \\
\text { perceptions of himself } & \text { and } & \text { others' } \\
\text { perceptions of him } & & & \\
\end{array}$ & 1 & $1 \%$ & 29 & Low \\
\hline 49 & Know the rights granted to me & 1 & $1 \%$ & 29 & Low \\
\hline 52 & Know the rights of others & 1 & $1 \%$ & 29 & Low \\
\hline 53 & Determine the standard of rights arrangement & 1 & $1 \%$ & 29 & Low \\
\hline 54 & Rationale for prioritizing rights & 1 & $1 \%$ & 29 & Low \\
\hline
\end{tabular}




\begin{tabular}{|l|l|l|l|l|l|}
\hline The number & \multicolumn{1}{|c|}{ Life Skills } & Repetition & Percentage & Rank & Rating \\
\hline 55 & Influential role model & 1 & $1 \%$ & 29 & Low \\
\hline 58 & Appreciation of peace and stability & 1 & $1 \%$ & 29 & Low \\
\hline 60 & Reality Orientation & 1 & $1 \%$ & 29 & Low \\
\hline 61 & The investigation & 1 & $1 \%$ & 29 & Low \\
\hline 62 & Organized thought & 1 & $1 \%$ & 29 & Low \\
\hline 63 & Collaborative work & 1 & $1 \%$ & 29 & Low \\
\hline 11 & & 133 & $100 \%$ & & Total \\
\hline
\end{tabular}

It is clear from the data in the previous table that the degree of inclusion of life skills in the activities guide "interactive curriculum for activity classes" was low, so the percentages ranged between (7\% to $1 \%)$, and this may be due to the fact that, given the number of life skills, we note that Much greater than the number of classes that cover these skills in the activities guide, then the focus was on quantity rather than quality, so life skills are accumulated in the activities guide for the time allocated to teaching, which causes students to resort to memorization and retrieval to absorb the skills without understanding them, which makes them feel frustrated sometimes, which May prompt them to drop out of the ration.

This may be attributed to the authors of the activities 'belief in the importance of the skill of effective communication that achieves the highest levels of human interaction by investing all the capabilities of receiving and throwing by using the means and media that suit the student's situation in its spatial and temporal dimensions, to express feelings and needs in a smooth and simple way, so that both parties can absorb the message Accept all statements and deeds from the other party for the purpose for which this communication came.

This may be attributed to the awareness of the authors of the activities guide, the importance of including the skill of structured thinking, investigation, focus and attention of the student as a case of purposeful thinking that depends on an organized intellectual sequence that aims to enhance the student's knowledge to collect accurate, arranged and honest information, but these skills have a low degree of lack It is contained in the activities guide, except in one activity, despite the importance of these skills in the student's understanding of daily life, as the importance of organized thinking, investigation, focus and attention varies in various fields, which makes the student acquire a weapon when facing problems to know the student the skills that must be used, and the method That achieve an appropriate solution.

Second question: What is the degree of secondary school students acquiring the life skills that are available in the activities guide "interactive curriculum for activity classes"?

To answer this question, arithmetic averages and standard deviations were extracted to know the degree of secondary stage students' acquisition of life skills available in the activities guide "Interactive Curriculum for Activity Classes" in Jordan, and Table (2) shows that:

Table (2)

Mathematical Averages and Standard deviations to the point that the activities guide "interactive curricula for activities classes" in Jordan for life skills, they are listed in descending order

\begin{tabular}{|c|l|c|c|c|c|}
\hline $\begin{array}{c}\text { paragraph } \\
\text { number }\end{array}$ & \multicolumn{1}{|c|}{ The paragraph } & $\begin{array}{c}\text { Arithmetic } \\
\text { mean }\end{array}$ & $\begin{array}{c}\text { standard } \\
\text { deviation }\end{array}$ & Rank & Rating \\
\hline 3 & freedom of expression & 4.44 & .573 & 1 & High \\
\hline 13 & $\begin{array}{l}\text { Participation in collective decision- } \\
\text { making }\end{array}$ & 4.35 & .645 & 2 & High \\
\hline 20 & Self-reliance & 4.20 & .695 & 3 & High \\
\hline 9 & Self-assurance & 4.14 & .695 & 4 & High \\
\hline 4 & Know the rights granted to me & 4.12 & .655 & 5 & High \\
\hline 1 & Respect for the opinion of others & 3.95 & .842 & 6 & High \\
\hline 5 & time management & 3.93 & .895 & 7 & High \\
\hline 11 & The ability to make decisions & 3.70 & .588 & 8 & High \\
\hline 7 & Know the rights of others & 3.31 & 1.055 & 9 & Average \\
\hline 2 & Listening & 3.22 & .664 & 10 & Average \\
\hline 23 & Accept criticism & 2.80 & 1.221 & 11 & Average \\
\hline 15 & Initiative & 2.73 & 1.085 & 12 & Average \\
\hline 18 & Take responsibility & 2.67 & 1.066 & 13 & Average \\
\hline 6 & Tolerance & 2.61 & .918 & 14 & Average \\
\hline 21 & $\begin{array}{l}\text { Refuse the unacceptable social } \\
\text { postulates }\end{array}$ & 2.51 & 1.230 & & Average \\
\hline 16 & The pursuit of self-development & 2.32 & .999 & 16 & Low \\
\hline
\end{tabular}




\begin{tabular}{|c|l|c|c|c|c|}
\hline $\begin{array}{c}\text { paragraph } \\
\text { number }\end{array}$ & \multicolumn{1}{|c|}{ The paragraph } & $\begin{array}{c}\text { Arithmetic } \\
\text { mean }\end{array}$ & $\begin{array}{c}\text { standard } \\
\text { deviation }\end{array}$ & Rank & Rating \\
\hline 12 & $\begin{array}{l}\text { Implement the decision and bear its } \\
\text { results }\end{array}$ & 2.31 & 1.322 & 17 & Low \\
\hline 17 & Passive adjustment & 2.26 & 1.234 & 18 & Low \\
\hline 19 & Attention to personal cleanliness & 2.12 & .874 & 19 & Low \\
\hline 22 & Attention to clean environment & 1.89 & .796 & 20 & Low \\
\hline 8 & Etiquette of permission & 1.85 & .679 & 21 & Low \\
\hline 10 & Preserving personal property & 1.85 & .673 & 22 & Low \\
\hline 14 & $\begin{array}{l}\text { Giving sufficient time for the } \\
\text { decision-making process }\end{array}$ & 1.84 & .920 & 23 & Low \\
\hline 24 & Volunteer work & 1.62 & .620 & 24 & Low \\
\hline Total & freedom of expression & 2,95 & 20.944 & & Average \\
\hline
\end{tabular}

It is clear from the data in the previous table that to know the degree of secondary school students acquiring the life skills available in the activities guide, "the interactive curriculum for activity classes" in Jordan was a medium degree, so the arithmetic averages ranged between (4.44 to 1.62), and with regard to the overall degree was medium, This is due to the mean of the arithmetic average of (2.95), and this may be due to the students 'belief that the teacher based on the activity cannot activate it in a manner that ensures the achievement of all the skills mentioned in the activities guide, due to the large number of life skills mentioned in the activities guide, and the lack of training of the responsible teacher on Activity classes for dealing with students in a practical and theoretical way enjoyable, stimulating and feasible to achieve the desired goal of activity classes, and accordingly, a good focus must be placed on the integration between the results of the activities of the guide and the goals of other subjects in a manner that ensures a balanced growth of the personality of the students.

This may be due to the awareness of those responsible for developing the Activity Manual of the importance of developing the freedom of expression skill of students; To be able to express their thoughts and opinions through speech, writing, or any other way, it is the basis for the democratic system of the state, provided that the restrictions and procedures of freedom of expression that students learn through lessons of activity are taught by the teacher; In order to regulate the use of freedom, and to preserve national laws, people's rights, public morals, and public order.

This may be attributed to the authors of the activities manual. They ignoring the importance of the skills of the environment and volunteer work, despite the occupation of these skills is very important, especially in our current situations and the spread of the Corona virus, and the crises it caused. In addition to the need for the responsible teacher to focus on his students' awareness of the importance of these skills, their relationship to their lives, and the desired benefit from them; Because the cleanliness of the environment and voluntary work is one of the main factors for preserving society and the family, which creates a feeling of safety. However, what stands in the way of the teacher and his students, that the skills of volunteer work and the preservation of the environment may need practical application outside the walls of the school in addition to work inside the school, which gives students an opportunity to take social responsibility and allow them to provide assistance, and the ability to reach constructive solutions that make them individual. They have a strong personality, they feel confident of themselves and they are able to deal with people older than them age and culture, so the process of exchanging experiences between them and the circle of knowledge and relationships widens.

\section{Recommendations:}

Based on the results of the study, the study recommended the following:

1- Making use of the results of this study to review the activities guide, "the interactive curriculum for activity shares", and taking into consideration the priority of life skills.

2- Coordinate between authors of activities and other institutions in the country and international organizations, which deals with life skills.

3- Conducting more studies on life skills that should be included in the content of the activities guide, "the interactive curriculum for activity classes" in the Ministry of Education in Jordan in and focusing on other variables, given the recent application of the activities guide.

4- The necessity to focus on life skills related to preserving the environment and cooperative work when preparing the guide for activities and curricula.

\section{References}

Abu Sabya, M and Al-Hadidi, M. (2018). The degree to which life skills are available in the content of the sixthgrade English curriculum and the degree to which students acquire them from the viewpoint of their teachers in the capital, Amman. Educational Science Studies, 45 (3), 47-55. 
Al-Jazi, H and Al-Rusaei, M and Saleh, R and Al-Hallilat, K. (2016). The degree of inclusion of life skills in science books for the first three grades in Jordan. Educational Science Studies, 43 (5), 41-60.

Abboud, A. (2016). Life skills included in high school social studies textbooks. A research that is not published. Al-Hussein Bin Talal University, Jordan.

Al-Youssef, R. (2013). Social skills and its relationship to perceived self-efficacy and general academic achievement among a sample of middle school students in the Hayel region of Saudi Arabia in the light of a number of variables. Journal of the Islamic University for Educational and Psychological Studies, 21 (1), 327-365.

Eteokleous, N. (2011). Developing Youths Cultural and Social Skills Through Asocial - Virtual Curriculum.Journal Multicultural Education and Technology, 5(3):221-238.

Hayek, A. (2014). Reality of life skills development: an analytical study of the content of the Arabic language curriculum at the secondary level. Research that is not published. Yarmouk University, Jordan.

Ige, A. (2011). The Challenges Facing Early Childhood Care. Development and Education (ECCDE) in an Era of Universal Basic Education in Nigeria, Early Childhood Education Journal, (39), 161 - 167.

Sarmad, G. Habiby, S and Arvantan, M. (2012). Survey and Analysis on Content of primary Education Textbooks from Life Skills Training Point of View. Journal of Life Science and Biomedicine, 2 (5), 231 - 238.

Shawish, I. (2010). The health concepts included in the science books for the sixth and seventh grades in Jordan. A research that is not published. Mu'tah University, Jordan.

The Ministry of Education. (2019). Activity guide "Interactive curriculum for activity classes". Amman, Jordan. Retrieved from http://www.moe.gov.jo. on February 2, 2020,

The Ministry of Education. (2020). The Ministry of Education's Strategic Plan 2018 - 2020. Amman: Jordan.

Retrieved on March 10, 2020, from http://www.moe.gov.jo.

UNICEF. (2009). Life Skills Definition of Terms. Retrieved March 2020, from: http://www.Unicef.org/Lifeskills/index-7308html. 